\title{
DESIGN AND IMPLEMENTATION OF A LABORATORY EQUIPMENT FOR STUDYING HEAT TRANSFER BY CONDUCTION
}

\author{
István PADRAH, ${ }^{1}$ Judit PÁSZTOR, ${ }^{2}$ Rudolf FARMOS ${ }^{3}$ \\ Sapientia Hungarian University of Transylvania, Faculty of Technical and Human Sciences, Târgu Mures, \\ Romania, \\ 1 isti207@yahoo.com \\ ${ }^{2}$ pjudit@ms.sapientia.ro \\ 3farmos_rudolf@ms.sapientia.ro
}

\begin{abstract}
Thermal conduction is a heat transfer mechanism. It is present in our everyday lives. Studying thermal conductivity helps us better understand the phenomenon of heat conduction. The goal of this paper is to measure the thermal conductivity of various materials and compare results with the values provided by the manufacturers. To achieve this we assembled a measuring instrument and performed measurements on heat insulating materials.
\end{abstract}

Keywords: heat transfer, thermal conductivity, thermal conductivity factor, heat-insulating material.

\section{Introduction}

For engineering students it is important to link the theoretical knowledge of various phenomena and processes with practice, in order to provide better understanding of the subjects. Instructional equipment is able to illustrate processes that are a combination of both concrete and abstract concepts. Thermal phenomena, such as heat transfer, are abstract processes, so their illustration is very important for future engineers.

The spreading of heat is an energy transfer, which occurs because of a temperature difference. The phenomenon's fundamental processes are thermal conduction, thermal convection, and thermal radiation.

Thermal conduction takes place in solid objects and in fluids and gases in a stationary state. The spreading of heat in solid objects occurs by the vibration of atoms, by elastic elementary waves, and the diffusion of free electrons in the conductors also contribute to this phenomenon [1]. In fluids and gases the molecular displacement is significant, here the heat conduction is due to inordinate thermal movement. In this latter case it's the collisions that deliver the energy from the warmer side to the cooler side [2].

Convection occurs in flowing media. The particles move relative to each other macroscopically and by this movement they carry their energy with them [1].

In the case of radiation there is no transmitting medium, the energy is spreading in the form of electromagnetic waves.

In this paper we present an item of equipment we created that provides a better understanding of the process of thermal conduction.

The mathematical model of heat transfer has been determined by Fourier. According to this theory, in a homogeneous object the stationary heat flux is directed towards the decreasing temperatures, [1]. The mathematical phrasing of Fourier's law is stated in equation (1):

$$
\dot{q}=-\lambda \cdot \operatorname{grad} T\left[\frac{W}{m^{2}}\right]
$$

where:

$q$ - thermal flux density, $\left[\mathrm{W} / \mathrm{m}^{2}\right]$;

$\lambda$ - thermal conductivity, $[\mathrm{W} /(\mathrm{m} \cdot \mathrm{K})]$;

$\Delta T$ - temperature difference $[\mathrm{K}]$. 
In a single dimension the heat flux is proportional to the spreading direction experienced per unit length, to the temperature change and to the area perpendicular to the direction of this cross-section:

$$
\dot{Q}=-\lambda \cdot A \cdot \Delta T / \Delta x \quad[W]
$$

where:

$Q$ - heat flux, [W];

$\lambda$-thermal conductivity $[\mathrm{W} /(\mathrm{m} \cdot \mathrm{K})]$;

$A$ - area of cross-section $\left[\mathrm{m}^{2}\right]$;

$\Delta T$ - temperature difference, [K];

$\Delta x$ - distance between the cold and the warm sides, [m].

Relationships (1) and (2) are true only for stationary systems. Therefore, in the course of the experiments one has to wait for the temperature on the hot and cold sides to stabilize at the given value.

Thermal conductivity is a physical property of materials, its numerical value depends on the structure of the material and on the thermodynamic state of the material. Its measurement is complicated, and it is typically carried out in specialized laboratories. The thermal conductivity of some materials can be found in various manuals and it can also be found on the Internet.

Fourier's law in this case of plain wall equation becomes as follows:

$$
\dot{Q}=-\lambda \cdot A \cdot \frac{t_{2}-t_{1}}{\delta}[W],
$$

where:

$Q$ - heat flux, [W];

$\lambda$-thermal conductivity coefficient, $[\mathrm{W} /(\mathrm{m} \cdot \mathrm{K})]$;

$A$ - area of cross-section, $\left[\mathrm{m}^{2}\right]$;

$\left(t_{2}-t_{1}\right)$ - temperature difference between the plain wall's two sides, $\left[{ }^{\circ} \mathrm{C}\right]$;

$\delta$-plain wall thickness [m].

Calculation of thermal conductivity:

$$
\lambda=\left|-\frac{\dot{Q}}{A \cdot \frac{t_{2}-t_{1}}{\delta}}\right|\left[\frac{W}{m \cdot K}\right]
$$

The thermal conductivity is dependent the temperature. This dependence is most often modeled according to the following simplified correlation [2]:

$$
\lambda=\lambda_{0} \cdot(1+b \cdot t)\left[\frac{W}{m \cdot K}\right]
$$

where:

$t$ - the temperature, $\left[{ }^{\circ} \mathrm{C}\right]$;

$\lambda_{0}$ - the thermal conductivity measured at a reference temperature, $[\mathrm{W} /(\mathrm{m} \cdot \mathrm{K})]$.

\section{Measurements and data processing}

\subsection{Principle of measurement}

For the determination of the thermal conductivity we designed the equipment to operate on a steady state absolute measurement method, based on the "Hot Plate" principle, which is shown in Figure 1.

The idea behind the method is to create a temperature difference between the two sides of the specimen, which causes a heat flux from the warmer side towards the cooler side. At equilibrium, after constant heat flow has set in, the heat conductivity coefficient of the sample can be calculated from the heat flux, the thickness of the specimen and the temperature difference, according to relation (4).

\subsection{Structure of the measuring equipment}

To determine the thermal conductivity of a plane wall there is a need for a controllable heat source to help set the different experimental conditions; a frame, on which the measuring instruments - in this case temperature sensors can be placed; measuring systems for measuring and data recording. The plane wall needs to be attached to the frame and its thickness needs to be adjustable.

The experiment is designed to be performed during an educational session, which means that the measurement time should be less than 2 hours.

The basic principle of the construction of the measuring stand can be seen in Figure 2.

The designed and built equipment is shown in Figure 3. Parts: 1 control unit: control of heating device by a relay, Raspberry Pi as control unit; 2

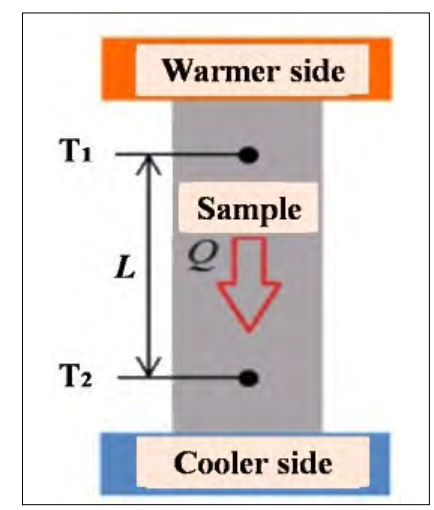

Figure 1. Principle of determining thermal conductivity [3] 


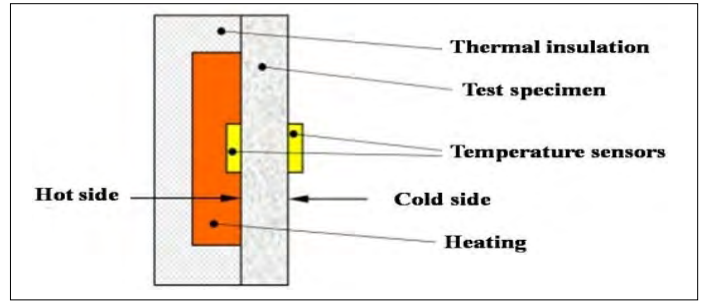

Figure 2. Schematic of the equipment

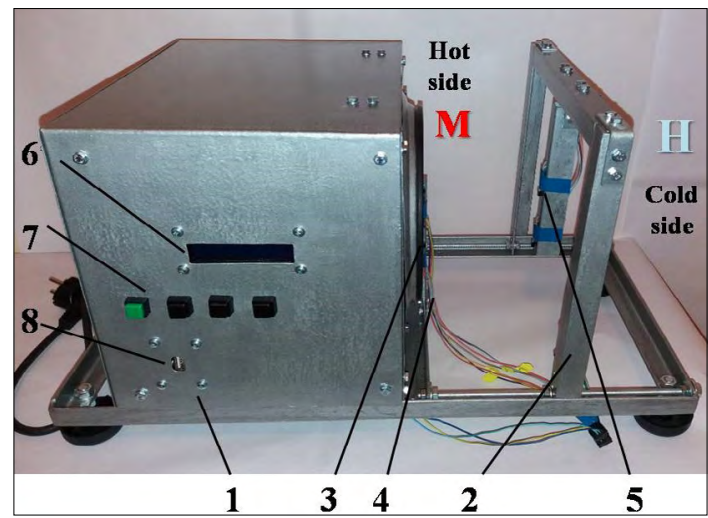

Figure 3. The constructed measuring device

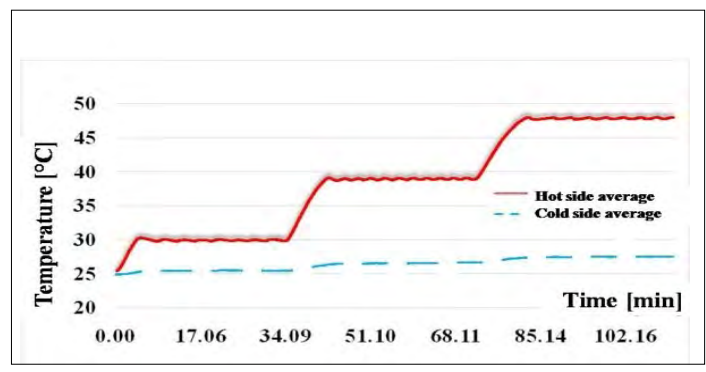

Figure 4. Temperature vs. Time plots of the cold and the hot sides

frame structure and plane wall mounting frame, 3 heating device, 4 and 5 temperature sensors, 6 display, 7 buttons, 8 data storage connector.

The relay is controlled with pulse-width-modulation (PWM), which provides the desired temperature of the hot plate.

During measurement the equipment was completely covered with a thermal insulation sheet.

\subsection{Performing the measurement}

The examined plane wall made of expanded polystyrene (expanded polystyrene insulation plate) was placed in the equipment. We adjusted the brackets to place the sensors as close to the plane wall as possible. After this we insulated the equipment.
The device was connected to the power supply. We turned on the main switch, inserted the USB memory drive into the connector and started the measurement with the start button.

From the start of the heating process the temperature values were measured on both sides of the plane wall, with two sensors on each side; (the warm and the cold side).

The first target temperature was $30^{\circ} \mathrm{C}$. After reaching the target temperature the heating plate was set to hold this temperature for 30 minutes, while the sensors collected the data. The measurement data was stored in USB memory.

Then the heating plate was heated up to the second target temperature, $40^{\circ} \mathrm{C}$, and at this point data was again collected for 30 minutes while the heating plate maintained the set temperature.

The third target temperature was $50^{\circ} \mathrm{C}$, therefore heating was performed again and the set temperature was kept constant for 30 minutes. The data during the measurement was also stored.

Achieving and maintaining target temperatures for a desired time must happen without external intervention. As a device user, we only need to monitor the process and check for possible errors. Emergency stop can be performed if necessary.

\subsection{Processing the data}

The equipment recorded a data point every 4 seconds, and saved it to a .csv file. The collected data is shown in Figure 4. :

Average values of temperatures measured on the warm side illustrate the steady-state sections and the planned temperature rise. Temperature increase can also be seen on the cold side, which indicates heat conduction through the plain wall.

Measurements were made at $20 \mathrm{~mm}, 50 \mathrm{~mm}$ and $80 \mathrm{~mm}$ wall thicknesses. The measurements were repeated three times. We calculated the mean values of the thermal conductivity at the steady-state sections according to correlation (4). The data is shown in Table 1.

The variation of thermal conductivity is illustrated in Figure 5.

The value of the thermal conductivity increased with the increase of temperature, as expected.

The thermal conductivity is a material property; it is independent of the wall thickness. For different wall thicknesses we received different thermal conductivity values with the equipment. The phenomenon can be explained by the insufficient insulation of the equipment, but the inhomoge- 
neous structure of the specimen can also cause the deviation.

The thermal conductivity coefficient of expanded polystyrene reference values is determined at $20^{\circ} \mathrm{C}$. Thermal conductivity coefficient value can be found between 0.035 and $0.050[\mathrm{~W} /(\mathrm{m} \cdot \mathrm{K})]$ [4].

Using the regression line equation from the experimental data, we calculated the thermal conductivity value at $20^{\circ} \mathrm{C}$ for all three wall thicknesses, and based on this we defined correction factors.

$\lambda_{20, \text { equipment }}=0.007 \cdot t+0.0689\left[\frac{\mathrm{W}}{\mathrm{m} \cdot \mathrm{K}}\right]$

$\lambda_{20, \text { equipment }}=0.007 \cdot 20+0.0689=0.0829\left[\frac{\mathrm{W}}{\mathrm{m} \cdot \mathrm{K}}\right]$

We calculated the correction factor at the middle of the interval, $\lambda_{20 \text {, referencia }}=0.043[\mathrm{~W} /(\mathrm{m} \cdot \mathrm{K})]$ :

$k=\frac{\lambda_{20, \text { reference }}}{\lambda_{20, \text { equipment }}}=\frac{0.043}{0.0829}=0.518$

Based on a similar calculation, we determined the correction factors for $50 \mathrm{~mm}$ and $80 \mathrm{~mm}$ wall thicknesses too; the results are summarized in Table 2.

The data measured with the instrument we constructed can be approximated with the following equation for polystyrene:

$\lambda=k \cdot \lambda_{20, \text { calculated }}\left[\frac{W}{m \cdot K}\right]$

\section{Conclusions}

Determining the thermal conductivity of a plane wall helps the understanding of the phenomenon of heat conduction.

Thermal conductivity values acquired with the measuring equipment differed from those given by the manufacturers. To make measurements more accurate it is recommended to create better thermal insulation for the equipment and include the heat loss of the equipment into the model.

\section{References}

[1] Bihari P.: 4. Hővezetés és hősugárzás. In: Müszaki hőtan. Edutus Főiskola, Budapest, 2012. https://www.tankonyvtar.hu/hu/tartalom/tamop412A/2010-0017_42_muszaki_hotan/ch04.html (accessed on $10^{\text {th }}$ February 2019)

[2] Kakucs A.: Müszaki hőtan. Scientia Kiadó, Kolozsvár, 2005. 150-160.
Table 1. The mean values of the measurement data for different wall thicknesses

\begin{tabular}{|c|c|c|c|}
\hline$\delta=20 \mathrm{~mm}$ & $\delta=50 \mathrm{~mm}$ & $\delta=80 \mathrm{~mm}$ & $\begin{array}{l}\text { Unit of mea- } \\
\text { surement }\end{array}$ \\
\hline $\mathrm{Q}_{30}=1.45$ & $\mathrm{Q}_{30}=1.22$ & $\mathrm{Q}_{30}=1.00$ & [W] \\
\hline $\mathrm{Q}_{40}=4.54$ & $\mathrm{Q}_{40}=4.23$ & $\mathrm{Q}_{40}=4.24$ & [W] \\
\hline $\mathrm{Q}_{50}=7.69$ & $Q_{50}=7.63$ & $\mathrm{Q}_{50}=8.17$ & [W] \\
\hline$\Delta \mathrm{t}_{30}=4.48$ & $\Delta \mathrm{t}_{30}=4.341$ & $\Delta \mathrm{t}_{30}=4.22$ & {$\left[{ }^{\circ} \mathrm{C}\right]$} \\
\hline$\Delta \mathrm{t}_{40}=12.43$ & $\Delta \mathrm{t}_{40}=13.01$ & $\Delta \mathrm{t}_{40}=13.16$ & {$\left[{ }^{\circ} \mathrm{C}\right]$} \\
\hline$\Delta \mathrm{t}_{50}=20.34$ & $\Delta \mathrm{t}_{50}=21.55$ & $\Delta \mathrm{t}_{50}=21.90$ & {$\left[{ }^{\circ} \mathrm{C}\right]$} \\
\hline$\lambda_{30}=0.19$ & $\lambda_{30}=0.19$ & $\lambda_{30}=0.25$ & {$[\mathrm{~W} /(\mathrm{m} \cdot \mathrm{K})]$} \\
\hline$\lambda_{40}=0.12$ & $\lambda_{40}=0.22$ & $\lambda_{40}=0.34$ & {$[\mathrm{~W} /(\mathrm{m} \cdot \mathrm{K})]$} \\
\hline$\lambda_{50}=0.13$ & $\lambda_{50}=0.24$ & $\lambda_{50}=0.40$ & {$[\mathrm{~W} /(\mathrm{m} \cdot \mathrm{K})]$} \\
\hline
\end{tabular}

Table 2. Correction factors for the measuring equipment

\begin{tabular}{|c|c|c|c|}
\hline & $\boldsymbol{\delta}=\mathbf{2 0} \mathbf{~ m m}$ & $\boldsymbol{\delta}=\mathbf{5 0} \mathbf{~ m m}$ & $\boldsymbol{\delta}=\mathbf{8 0} \mathbf{~ m m}$ \\
\hline $\begin{array}{c}\lambda_{20 . \text { calculated }} \\
{[\mathrm{W} /(\mathrm{m} \cdot \mathrm{K})]}\end{array}$ & 0.0829 & 0.1666 & 0.1856 \\
\hline$k$ & 0.518 & 0.2581 & 0.2316 \\
\hline
\end{tabular}

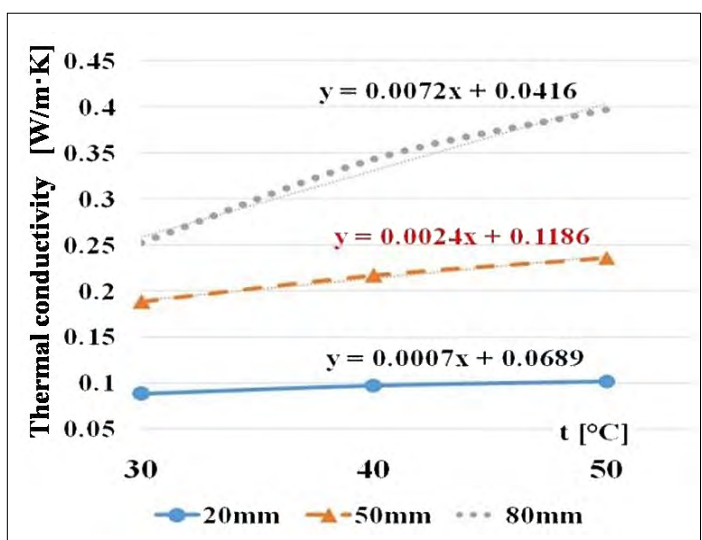

Figure 5. Measured thermal conductivity change as function of the temperature

[3] Dongliang Z., Xin Q., Xiaokun G.: Measurement Techniques for Thermal Conductivity and Interfacial Thermal Conductance of Bulk and Thin Film Materials. University of Colorado, Boulder, 2017. 5-10. (accessed on 15 Juny 2018)

h t t p s : / / a r i v.org/ftp/arxiv/pa pers/1605/1605.08469.pdf

[4] AV Group Hungary, Polisztirol dryvit hőszigetelés (accessed on $15^{\text {th }}$ May 2018).

http://www.szigeteloanyagarak.hu/polisztirol-hoszigeteles/polisztirol-dryvit-hoszigeteles/ 